\title{
TÉCNICOS, INTELECTUAIS E POLÍTICOS NA NOVA REPÚBLICA: UM PERFIL DOS DIRIGENTES PÚBLICOS DOS GOVERNOS FERNANDO HENRIQUE, LULA E DILMA
}

\author{
D’ARAÚJO, Maria Celina (org). Técnicos, intelectuais e políticos na nova República: um \\ perfil dos dirigentes públicos dos governos Fernando Henrique, Lula e Dilma. Rio \\ de Janeiro: Ed. PUC-Rio, 2018, 154 p.
}

Carla Michele Rech ${ }^{1}$

Compreender o Estado brasileiro, seus arranjos político-institucionais e especialmente a composição e atuação da burocracia, dos cargos de confiança e dos dirigentes públicos, tem mobilizado um conjunto expressivo de pesquisadores/as nos últimos anos. Após ter publicado em 2009 A elite dirigente do governo Lula, considerado um estudo inovador à época, dado que apresentava os resultados do perfil social e político dos cargos de alto escalão do governo federal na gestão de Lula (2003-2006 e 2007- ), Maria Celina D`Araújo avança em suas pesquisas e acaba lançando, em outubro de 2018, durante o $42^{\circ}$ Encontro Anual da Associação Nacional de Pós-Graduação e Pesquisa em Ciências Sociais (Anpocs), Técnicos, intelectuais e politicos na nova República: um perfil dos dirigentes públicos dos governos Fernando Henrique, Lula e Dilma. O livro recentemente lançado é produto de mais de uma década de trabalho de pesquisa empírica que cobre 18 anos de gestão pública federal, incluindo os governos Fernando Henrique, Lula da Silva e Dilma Rousseff (até fins de 2012).

O estudo de elites, segundo Petrarca e Oliveira ${ }^{2}$ (2016, p. 141) "constituem uma longa tradição nas ciências sociais, destacando-se como

\footnotetext{
1 Doutoranda no Programa de Pós-graduação em Sociologia da Universidade Federal do Rio Grande do Sul (UFRGS). Professora do Departamento de Sociologia e Politica da Universidade Federal de Pelotas (UFPel). Contato: carlatsul@yahoo.com.br. Pelotas-RS.

2 PRETARCA, F. R, OLIVEIRA, W. J.F. Os estudos de elites no Brasil: um ensaio crítico sobre a produção recente. In: REIS, E. T, GRILL, I. G. (orgs.) Estudos sobre elites politicas e culturais. Reflexões e aplicações não canônicas. São Luís: EDUFMA, 2016.
} 
uma importante área de investigação e objeto legítimo de pesquisa que tem suscitado divergentes interrogações, problemas de pesquisa e problemáticas teóricas e conceituais". Dentre as abordagens possiveis sobre esse tema, os autores destacam o trabalho de Pierre Bourdieu e sua equipe "na renovação e diversificação deste objeto (...) orientando o olhar para a investigação dos padrões de recrutamento e de seleção de individuos que ocupam posições elevadas em diferentes esferas sociais e não apenas na esfera política" (PETRARCA, OLIVEIRA, 2016, p. 142), tendo por base informações biográficas diversificadas. Coradini ${ }^{3}$ (2016, p. 127) destaca que "a própria terminologia utilizada para definir o tema geral, oscilando entre estudo de "elites", "classe dirigente", "grupos dirigentes", "grupos dominantes", entre outras, por um lado, é o resultado dos confrontos teóricos e metodológicos". Sem entrar no debate teórico-metodológico sobre o estudo das elites, D`Araújo e seus colaboradores procuraram conhecer a fundo o perfil profissional, social e acadêmico, bem como o envolvimento em movimentos da sociedade civil do que a autora denomina "dirigentes públicos": ocupantes de cargos na administração pública federal, de livre provimento, especificamente os cargos de direção e assessoramento (DAS) niveis 5 e 6 e os de natureza especial (NE) e que dada as regras existentes, podem tanto ser ocupados por funcionários de carreira da União quanto por pessoas do setor privado. Esses dirigentes públicos representam, ao lado do presidente e dos ministros, a elite que governa o país, segundo D`Araújo.

A pesquisa que originou o livro teve como referência a bibliografia que analisa a alta administração pública no Brasil a partir dos anos 1930 e a literatura internacional sobre a alta administração pública na Europa e Estados Unidos. Metodologicamente, para conhecer a fundo o perfil desses dirigentes, a pesquisadora coletou por mais de dez anos - tanto por meio da análise documental quanto pela realização de entrevistas e respostas a questionários respondidos por escrito ou presencialmente ao longo de dez anos - dados que permitiram examinar a biografia de 1.030 desses dirigentes, distribuídos em todos os ministérios, e de 406 ministros. Para realização de

3 CORADINI, O. L. As elites como objeto de estudo, novamente. In: REIS, E. T, GRILL, I. G. (orgs.) Estudos sobre elites politicas e culturais. Reflexões e aplicações não canônicas. São Luís: EDUFMA, 2016. 
um trabalho tão robusto, D`Araújo destaca que houve o envolvimento de mais de uma dezena de alunos de graduação e pós-graduação que colaboraram tanto com a coleta, processamento e organização de dados e tabelas quanto da escrita de textos. Além disso a pesquisa obteve, por um lado, financiamento da Fundação Ford até 2013 e, por outro, apoio da bolsa de pesquisa em produtividade do CNPQ, por todo período.

A qualidade do material apresentado representa também o acúmulo da pesquisadora na área. Maria Celina D`Araújo é pós-doutora pela Universidade da Flórida (1995), doutora e mestre em Ciência Politica e Sociologia pelo Instituto Universitário de Pesquisas do Rio de Janeiro (IUPERJ) (1989 e 1981) e graduada em Ciências Sociais pela Universidade Federal Fluminense (UFF) (1975). Atualmente é professora associada da Pontificia Universidade Católica do Rio de Janeiro (PUC-Rio), tendo sido anteriormente professora titular da Fundação Getulio Vargas (FGV) (1976 - 2009) e professora adjunta da UFF (1978 - 2005). Durante mais de quatro décadas de ensino e pesquisa, D’Araújo participou de diferentes maneiras em dezenas de livros publicados, seja como autora, organizadora ou colaboradora. Também tem publicado dezenas de artigos em revistas acadêmicas nacionais e internacionais. Estado e Governo, Defesa e integração regional, Forças Armadas, Comportamento político e Burocracia, servidores e dirigentes públicos têm sido suas subáreas de atuação.

A pesquisa empírica girou, segundo D`Araújo, em torno de oito eixos (gênero e etnia, procedência regional, origem funcional - vínculo com o serviço público ou privado - perfil político, atuação política na ditadura militar, escolaridade, ascensão social e filiação sindical) que foram convertidos em variáveis e utilizados de diferentes maneiras, dependendo do enfoque dado em cada um dos 5 capítulos que compõem o livro. Importante destacar que assim como em 2009, D`Araújo desenvolve suas análises tendo em vista a bibliografia disponivel sobre a alta administração pública no Brasil, bem como a literatura internacional sobre a alta administração pública na Europa e nos Estados Unidos. A partir daí, apresenta resultados que permitem identificar o perfil dos dirigentes públicos e, como no livro anterior, mantém uma análise comparativa. Em 2009, o trabalho foi realizado com ênfase na composição ministerial ao longo da Nova República, de Sarney a Lula, permitindo 
identificar tendências gerais e específicas que permearam cada governo. A obra atual foca na análise do perfil dos dirigentes públicos dos governos Fernando Henrique, Lula da Silva e Dilma Rousseff, e cada capítulo apresenta um recorte específico, como poderá ser observado na breve exposição realizada a seguir.

No capítulo 1, D`Araújo e Petek procuram observar empiricamente como se explicita a distinção no recrutamento e no perfil dos dirigentes públicos brasileiros do Ministério da Fazenda e Planejamento de um lado, e da Saúde e da Educação por outro. O objetivo das autoras é demonstrar, com base em dados empíricos, se em tempos democráticos foi mantido um padrão diferenciado no recrutamento e no perfil dos dirigentes destes ministérios e se ocorreram diferenças a esse respeito nos três governos. As autoras concluem que apesar das diferenças entre os três governos, a hipótese de que ministérios econômicos têm padrões diferenciados foi demonstrada, assim como a excepcionalidade do governo Lula e o boom participativo já destacado por D`Araújo na obra de 2009 e que não se repetiu com Dilma Rousseff. As análises demonstram que independente de diferenças de perfil, o país conta com quadros qualificados junto ao governo.

Já no capítulo 2, D`Araújo e Macedo apresentam dados sobre as mulheres dirigentes públicas que ocuparam cagos de DAS 5 e 6 e NE entre 1995 e 2012. Novamente a dimensão comparativa é mobilizada, comparando o perfil geral em relação aos homens que ocuparam os mesmos cargos e a evolução ao longo do período. As autoras demonstram que apesar das persistentes desigualdades de gênero, esse é um espaço em que as mulheres encontram menos obstáculos para a ascensão profissional. Destacam também que as mulheres dirigentes públicas são altamente escolarizadas e apresentam ainda, alto engajamento social (via militância em movimentos sociais ou a participação em associações), mesmo não tendo uma carreira politica eletiva. Os dados analisados pelas autoras indicam que, apesar de pífia, existe uma tendência crescente da participação feminina nos cargos de confiança do Poder Executivo, que até então eram tradicionalmente ocupados pelos homens. Apesar de serem majoritariamente brancas, destaca-se o crescimento da presença de mulheres afrodescendentes. As autoras destacam ainda que com maior ou menor partidarismo, todos esses quadros apresentam 
Técnicos, intelectuais e políticos na nova República | Carla Michele Rech

credenciais profissionais e acadêmicas para os cargos que ocupam, mesmo obedecendo a superiores políticos nem sempre tão preparados intelectualmente.

No capítulo 3 D`Araújo, Petek e Ribeiro apresentam dados sobre a escolaridade dos dirigentes públicos que ocupam cargos imediatamente abaixo dos ministros, incluindo graus de instrução, escolas e instituições formadoras e os principais cursos pelos quais passaram. Os autores demonstram que a alta escolaridade está consolidada e não varia de governo para governo, sendo este um espaço de alta seletividade há décadas. Destacam também a participação das instituições de ensino público e a importância das universidades federais na formação dos dirigentes. Além disso, mesmo os dirigentes formados no exterior tiveram apoio de bolsas de estudos financiados pelo governo federal. Outro aspecto relevante apontado pelos autores é que no Brasil a formação dos dirigentes não é concentrada em apenas algumas escolas ou cursos como ocorre em outros países, fato que se repete também nas análises em relação ao elenco de cursos frequentados, resguardadas as diferenças entre os niveis de formação. Os autores chamam atenção para o fato de que áreas antes prestigiadas como a medicina, foram saindo da cena política, dando lugar a novas áreas do conhecimento. Destacam também a relevância do curso de ciências sociais, que na graduação fica em quinto lugar nos cursos de formação e passa a ocupar o segundo lugar entre os dirigentes com título de doutorado.

No Capítulo 4, D`Araújo e Ribeiro dialogam com questões colocadas especialmente no primeiro capítulo, procurando identificar possíveis clivagens ou semelhanças no perfil dos dirigentes públicos, comparando ministérios de natureza distintas (duas áreas de politicas públicas: desenvolvimento e social; e uma área de articulação política, a Presidência da República). Segundo os autores, a mais importante contribuição deste capítulo é diagnosticar com mais precisão a esfera da Presidência da República. O objetivo dos autores foi verificar se a natureza do órgão demanda o recrutamento de tipos diferentes de dirigentes. Como já salientado nos outros capítulos, verificou-se que os dirigentes públicos são altamente escolarizados, mesmo não se apresentando de forma homogênea: a área social mais acadêmica, com maior número de mestres e doutores, enquanto a área do desenvolvimento é mais técnica, com 
número proporcionalmente maior de especialistas. Verificou-se também que os dirigentes destas três áreas tem experiência em administração pública visto que estão mais vinculados ao serviço público federal, observadas as diferenças na procedência regional dos recrutados. Os autores destacam que esses dirigentes têm em comum o fato de serem fortemente mobilizados, sendo os da área social aqueles com maior histórico de participação social e política, seguidos dos dirigentes da Presidência da República. No caso da Presidência da República, o conjunto de dados demonstra ainda que a participação de não servidores é maior que nas outras duas áreas e sugere, segundo os autores, que nesse espaço se aplica uma conciliação entre recrutamento baseado em critérios técnicos e politização.

Por fim, no capítulo 5, D`Araújo e Ribeiro apresentam dados específicos sobre os ministros no período da Nova República (1985 - 2014), ampliando o período pesquisado nos capítulos anteriores. Conforme já destacado anteriormente, os pesquisadores trabalharam com informações de 406 dos 467 ministros nomeados ao longo do período, mesmo que o número de nomeações tenha sido maior (522), visto que durante o mesmo governo determinado ministro pode trocar de pasta e as repetições de nomes foram excluídas. Segundo os autores, os ministros pesquisados são pessoas experientes na vida política, com forte enraizamento em atividades parlamentares, contrariando a tendência que se observa nas democracias europeias. Os dados indicam ainda que este é um espaço importante para quem percorreu longa carreira política, dado a faixa etária dos ministros (acima de 50 anos), mesmo que não seja especialista no assunto da pasta. Destacam ainda diferenças na procedência regional e do ponto de vista político-partidário, a emergência tímida das mulheres e afrodescendentes e a relação do arranjo institucional em presidencialismos de coalizão com a nomeação dos ministros. Fica evidente também, que apesar das tendências gerais existem diferenças entre os governos, muito bem destacadas pelos autores.

$\mathrm{Na}$ introdução do livro, D`Araújo observava que apesar das importantes reflexões sobre o tema da alta administração do Poder Executivo no Brasil, não havia até o momento, uma pesquisa que desse a conhecer de forma sistemática as características desse grupo e que permitisse assegurar 
se experiência profissional, qualificação técnica ou vínculos políticos são ou não padrões dominantes nessas nomeações. Podemos afirmar, com a leitura deste livro, que tal lacuna certamente está preenchida e é um convite à leitura, tanto por especialistas quanto pelo público em geral, tendo em vista que o texto é claro, objetivo, com gráficos e tabelas que auxiliam na demonstração dos dados encontrados. Apesar da qualidade e profundidade do trabalho, as autoras retomam o que elas consideram uma questão clássica e infindável da literatura sobre as articulações entre burocratas, políticos e processo decisório ao apontar que "o eixo da discussão deveria ir além das formas de recrutamento e do perfil dos dirigentes, para entender como quadros tão preparados tecnicamente, de um lado, e tão socialmente engajados, de outro, não correspondem a incrementos mais rápidos nos problemas estruturais do país" (p. 52). Ademais, a medida que novos governos são eleitos, serão necessárias novas investigações e, com a base de dados disponível hoje sobre os governos anteriores, será possível verificar a manutenção ou a ruptura com tendências históricas em relação ao perfil social e político dos cargos de alto escalão do governo federal brasileiro. 